\title{
Alterations in acid-base balance, blood gases, and hematobiochemical profiles of whole-blood and thoracic fluid in goats with contagious caprine pleuropneumonia
}

\author{
Mohamed Tharwat ${ }^{1,2}$ id \\ 1. Department of Veterinary Medicine, College of Agriculture and Veterinary Medicine, Qassim University, P.0. Box 6622, \\ Buraidah, 51452, Saudi Arabia; 2. Department of Animal Medicine, Faculty of Veterinary Medicine, Zagazig University, \\ 44519, Zagazig, Egypt. \\ Corresponding author: Mohamed Tharwat, e-mail: mohamedtharwat129@gmail.com \\ Received: 27-03-2021, Accepted: 11-06-2021, Published online: 20-07-2021
}

doi: www.doi.org/10.14202/vetworld.2021.1874-1878 How to cite this article: Tharwat M (2021) Alterations in acid-base balance, blood gases, and hematobiochemical profiles of whole-blood and thoracic fluid in goats with contagious caprine pleuropneumonia, Veterinary World, 14(7): 1874-1878.

\begin{abstract}
Background and Aim: Contagious caprine pleuropneumonia (CCPP) is a highly contagious and fatal disease affecting goats and some wild ruminants. It is a cause of major economic losses in the goat industry in Africa, Asia, and the Middle East. This study aimed to investigate the acid-base balance, blood gases, and hematobiochemical profiles of whole-blood and fluid collected from the thoracic cavity in goats with CCPP.

Materials and Methods: Fifty-five goats suffering from weight loss, anorexia, dyspnea, polypnea, cough, and nasal discharges due to CCPP were studied. Twenty-five healthy goats were used as controls. Diseased animals were enrolled in this study based on a positive serological latex agglutination test (LAT) that confirmed the detection of Mycoplasma capricolum subsp. capripneumoniae. The control goats were enrolled based on a negative result of the LAT.

Results: Compared with a mean value of $7.38 \pm 0.04$ in controls, the $\mathrm{pH}$ in the diseased group was $7.41 \pm 0.05$. The blood pressure of carbon dioxide $\left(\mathrm{PCO}_{2}\right)$, pressure of oxygen $\left(\mathrm{PO}_{2}\right)$, base excess $(\mathrm{BE})$, bicarbonate $\left(\mathrm{HCO}_{3}\right)$, total carbon dioxide $\left(\mathrm{TCO}_{2}\right)$, and saturation of oxygen $\left(\mathrm{SO}_{2}\right)$ were lower in goats with CCPP than in controls. However, the anion gap (AnGap) was higher in the diseased goats than in the healthy ones. Compared with the levels in blood samples, the thoracic fluid $\mathrm{PCO}_{2}, \mathrm{PO}_{2}, \mathrm{BE}$, and $\mathrm{SO}_{2}$ were higher while $\mathrm{pH}, \mathrm{HCO}_{3}, \mathrm{TCO}_{2}$, and AnGap were lower. Compared with the findings in healthy goats, hematological alterations included significant increases in white blood cells and neutrophils, and a significant decrease in the red blood cell count. In the thoracic fluid, neutrophilic leukocytosis was a remarkable finding. The serum concentrations of globulin, blood urea nitrogen, and glucose, and the activities of aspartate aminotransferase (AST) and $\gamma$-glutamyl transpeptidase (GGT) increased significantly compared with those in controls. In contrast, serum concentrations of albumin, calcium, and magnesium, and the activity of alkaline phosphatase (ALP) decreased significantly compared with those of healthy animals. The activities of ALP, AST, GGT, and creatine kinase and the concentration of phosphorus were higher in thoracic fluid than the serum values in the diseased group.
\end{abstract}

Conclusion: When compared with the healthy controls, goats with CCPP have metabolic acidosis. Compared with the levels in healthy goats, the blood $\mathrm{PCO}_{2}, \mathrm{PO}_{2}, \mathrm{BE}, \mathrm{HCO}_{3}, \mathrm{TCO}_{2}$, and $\mathrm{SO}_{2}$ are low in goats with CCPP; however, the AnGap is higher in diseased goats.

Keywords: acid-base balance, blood gases, contagious caprine pleuropneumonia, goat, Mycoplasma.

\section{Introduction}

Contagious caprine pleuropneumonia (CCPP) is a highly contagious severe mycoplasmal disease that affects the vast majority of goat populations and is caused by Mycoplasma capricolum subsp. capripneumoniae (Mccp). This disease rarely affects sheep and does not infect cows [1]. CCPP has been reported to have a wide distribution among sheep and goats covering diverse areas, especially in Africa and Asia [2]. This disease is economically devastating for the goat

Copyright: Tharwat. Open Access. This article is distributed under the terms of the Creative Commons Attribution 4.0 International License (http://creativecommons.org/licenses/by/4.0/), which permits unrestricted use, distribution, and reproduction in any medium, provided you give appropriate credit to the original author(s) and the source, provide a link to the Creative Commons license, and indicate if changes were made. The Creative Commons Public Domain Dedication waiver (http://creativecommons.org/ publicdomain/zero/1.0/) applies to the data made available in this article, unless otherwise stated. industry in Africa, Asia, and the Middle East [3-5]. Goats that are raised in over 40 countries globally are affected by CCPP, so it poses a serious threat to the goat industry worldwide [1].

CCPP mainly affects the respiratory system. It is characterized in its acute form by fever, anorexia, and severe respiratory symptoms including cough, nasal discharge, difficulty breathing, increased respiratory rate, and pleuropneumonia [6]. The diagnosis of CCPP in veterinary clinics depends on both clinical and postmortem examinations, which should be confirmed by laboratory tests [4]. Confirmation of $M c c p$ is carried out by different methods, including microscopic examination of pulmonary exudation, histopathology of pulmonary parenchyma, molecular identification, and typing, namely, by polymerase chain reaction (PCR), detection of antigen in affected tissue by gel precipitin tests, and characterization by 
modern serological techniques [1]. The more recently developed methodologies include the latex agglutination test (LAT), competitive enzyme-linked immunosorbent assay, PCR, and restriction fragment length polymorphism [1,7-9]. Evaluation of cavity fluids including abdominal, thoracic, and pericardial effusions in the laboratory is beneficial for evaluating disease severity $[10,11]$.

Grossly, consolidation of the lungs is the main finding in CCPP-affected goats, followed by alveolar exudation and pleural fluid accumulation and pleural adhesion, along with fibrinous pleuritis and peribronchial cuffing of inflammatory mononuclear cells in pulmonary tissue [2]. During the progression of CCPP, changes of various hematobiochemical variables have been reported in mycoplasma-affected goats compared with the findings in control ones. These changes included anemia, leukocytosis followed by leukopenia, hypoproteinemia, hypoalbuminemia, and elevated aspartate aminotransferase (AST), alanine aminotransferase, calcium, glucose, and globulin [1]. Therefore, it is expected that blood $\mathrm{pH}$ and blood gases will differ significantly compared with those of healthy goats, so it is vital to also treat the acid-base disturbances. It was recently reported that controlling the acid-base status will increase the value of therapies for many human diseases [12].

This investigation was designed to study the acid-base status and blood gases in goats with CCPP using whole-blood samples and also fluid collected from the thoracic cavity. In parallel with this, the hematobiochemical profiles were also investigated in both samples.

\section{Materials and Methods}

\section{Ethical approval}

The study design was approved by the Animal Ethical Committee, Deanship for Scientific Research, Qassim University, Saudi Arabia (approval number 2015-3436). The goats were maintained and treated according to the Laboratory Animal Control Guidelines of Qassim University, which basically conform to the Guide for the Care and Use of Laboratory Animals of the National Institutes of Health in the USA (NIH publications No. 86 to 23, revised 1996).

\section{Study period and location}

The study was conducted from February 2010 to August 2015 at the Veterinary Teaching Hospital, Qassim University, Saudi Arabia.

\section{Experimental group}

The experimental design has been reported previously [4]. Briefly, 55 goats aged $2.5 \pm 1.1$ years and weighing $26.4 \pm 10.1 \mathrm{~kg}$, which suffered from decreased body weight, complete loss of appetite, and respiratory symptoms including difficulty breathing, increased respiratory rate, coughing, and profound nasal execrations were examined. All of the goats with CCPP had positive LAT results [4].

\section{Control group}

Healthy goats $(\mathrm{n}=25$, age $2.8 \pm 0.9$ years; weight $31.0 \pm 12.7 \mathrm{~kg}$ ) were used as a control group. All of the healthy animals had a negative LAT result [4].

\section{Blood sampling and owners' agreement}

From each goat, a $7 \mathrm{~mL}$ blood sample was collected: $2 \mathrm{~mL}$ in an ethylenediaminetetraacetic acid (EDTA) tube and $5 \mathrm{~mL}$ in a heparinized tube. The diseased goats in this study were included in the investigation after the provision of informed agreement from their owners, and permission to euthanize and examine the goats at necropsy was given.

\section{Sampling of thoracic fluid}

The selected area for collecting pleural fluid was aseptically prepared, after which it was injected with lidocaine hydrochloride ( $5 \mathrm{~mL}$ of $2 \%$ ) as a local anesthetic. First, a small skin incision was made with a scalpel point, followed by ultrasound-guided insertion of an $18 \mathrm{~g} \times 80 \mathrm{~mm}$ needle into the pleural cavity. Seven milliliters of thoracic fluid were then withdrawn from the diseased group and placed in EDTA $(2 \mathrm{~mL})$ and heparin tubes $(5 \mathrm{~mL})$. Unfortunately, no fluid was imaged in the control goats, so no pleural fluid was collected from the controls to be analyzed for comparison with data from sick goats.

\section{Acid-base and blood gas analyses}

A portable clinical veterinary analyzer (I-STAT ${ }^{\circledR}$, Abaxis, California, USA) was used to evaluate the acid-base status and blood gases in the heparinized blood samples. The $\mathrm{pH}$, pressure of oxygen and carbon dioxide $\left(\mathrm{PO}_{2}\right.$ and $\mathrm{PCO}_{2}$, respectively), bicarbonate $\left(\mathrm{HCO}_{3}\right)$, base excess (BE), total carbon dioxide $\left(\mathrm{TCO}_{2}\right)$, saturation of oxygen $\left(\mathrm{SO}_{2}\right)$, AnGap, sodium, and chloride were measured immediately to stop changes in these variables [13]. Measurements of acid-base and blood gas analyses were carried out in 38 samples of whole blood, 15 thoracic fluid samples, and 15 samples of whole blood in the control goats.

\section{Determination of hematological and biochemical parameters}

Total leukocytic count and its subsets erythrocyte count, hematocrit (HCT), and hemoglobin were determined for the EDTA samples using VetScan HM5 (Abaxis, CA, USA). For the heparinized blood samples, an automated biochemical analyzer was used to measure the concentrations of blood urea nitrogen (BUN), calcium, phosphorus, magnesium, glucose, total protein (TP), albumin, and globulin (VetScan VS2, Abaxis, California, USA). The serum activities of AST, $\gamma$-glutamyl transferase (GGT), alkaline phosphatase (ALP), and creatine kinase (CK) were also determined by VetScan VS2. Determination of hematological and biochemical parameters was carried out in 38 samples of whole blood, 15 thoracic samples, and 15 samples of whole blood in the control goats. 


\section{Statistical analysis}

Data were assessed for normality using the D'Agostino Pearson test. The data were presented as means \pm standard deviations since no significant deviation from normality was observed. Data were analyzed statistically using the Statistical Package for Social Sciences program version 25.0, (IBM, Chicago, USA) [14]. A paired t-test for repeated samples was used to compare the acid-base status, blood gases, and hematobiochemical variables between goats with CCPP and the healthy ones. The significance was set at $p \leq 0.05$.

\section{Results}

Compared with the levels in the heparin blood samples, the thoracic fluid $\mathrm{PCO}_{2}, \mathrm{PO}_{2}, \mathrm{BE}$, and $\mathrm{SO}_{2}$ levels were high while $\mathrm{pH}, \mathrm{HCO}_{3}, \mathrm{TCO}_{2}$, and AnGap were low. Table- 1 displays the means $\pm \mathrm{SD}$ and the $25 \%$, $50 \%, 75 \%$, and $95 \%$ percentiles of acid-base balance and blood gases of blood samples collected from goats with CCPP versus healthy control goats. Compared with a mean value of $7.38 \pm 0.04$ in controls, the $\mathrm{pH}$ in the diseased group was $7.41 \pm 0.05$, with no significant difference between them $(\mathrm{p}=0.2)$. Compared with the values in healthy animals, the blood $\mathrm{PCO}_{2}, \mathrm{PO}_{2}, \mathrm{BE}$, $\mathrm{HCO}_{3}, \mathrm{TCO}_{2}$, and $\mathrm{SO}_{2}$ were lower in diseased goats $(p<0.05)$. However, the AnGap was higher in the diseased goats than in healthy ones $(p<0.05)$.

Neutrophilic leukocytosis was a remarkable finding in the thoracic fluid. The hematological profiles in goats with CCPP compared with those of control animals are shown in Table-2. Compared with controls, hematological alterations included significant elevations in white blood cells (WBCs) and neutrophils $(p<0.05)$. In contrast, the red blood cell (RBC) count in affected goats decreased significantly compared with that in healthy goats $(\mathrm{p}=0.0005)$. Other hematological measurements including lymphocytes, monocytes, hemoglobin, and HCT did not differ significantly when compared with those of controls $(\mathrm{p}>0.05)$.

The activities of ALP, AST, GGT, and CK and the concentration of phosphorus were higher in thoracic fluid than those in serum in diseased goats. Table-3 shows different biochemical parameters in goats with CCPP compared with those of healthy control animals. The serum levels of globulin, BUN, and glucose, and the activities of AST and GGT increased significantly compared with those of controls $(p<0.05)$. On the other hand, the serum levels of albumin, calcium, and magnesium, and the activity of ALP decreased significantly compared with those of healthy goats $(p<0.05)$. Other biochemical variables including the serum concentrations of TP and phosphorus, and the activity of CK did not differ significantly compared with the controls $(\mathrm{p}=0.1)$.

\section{Discussion}

In the present study, thoracic fluid samples were difficult to be collected from the control goats for

Table-1: Acid-base balance and blood gases in goats with contagious caprine pleuropneumonia versus healthy controls.

\begin{tabular}{|c|c|c|c|c|c|c|c|c|c|c|c|}
\hline \multirow[t]{3}{*}{ Parameters } & \multicolumn{5}{|c|}{ Whole blood $(n=38)$} & \multicolumn{5}{|c|}{ Controls $(n=15)$} & \multirow[t]{3}{*}{ p-value } \\
\hline & \multirow[t]{2}{*}{ Mean \pm SD } & \multicolumn{4}{|c|}{ Percentiles (\%) } & \multirow[t]{2}{*}{ Mean \pm SD } & \multicolumn{4}{|c|}{ Percentiles (\%) } & \\
\hline & & 25 & 50 & 75 & 95 & & 25 & 50 & 75 & 95 & \\
\hline$\overline{\mathrm{pH}}$ & $7.41 \pm 0.05$ & 7.39 & 7.43 & 7.44 & 7.45 & $7.38 \pm 0.04$ & 7.38 & 7.41 & 7.45 & 7.52 & 0.2 \\
\hline $\mathrm{PCO}_{2}(\mathrm{mmHg})$ & $29.8 \pm 5.6$ & 24.9 & 28.4 & 33.9 & 38.6 & $39.9 \pm 6.3$ & 35.6 & 37.9 & 43.8 & 50.6 & $<0.0001$ \\
\hline $\mathrm{PO}_{2}(\mathrm{mmHg})$ & $28 \pm 4$ & 25 & 27 & 33 & 34 & $38 \pm 6.4$ & 35 & 36 & 43 & 48 & 0.002 \\
\hline $\mathrm{BE}^{2}(\mathrm{mmol} / \mathrm{L})$ & $-5.9 \pm 4.8$ & -7.3 & -5.5 & -4.0 & 1.5 & $1.9 \pm 4.7$ & 0.0 & 3.0 & 4.0 & 8.2 & $<0.0001$ \\
\hline $\mathrm{HCO}_{3}(\mathrm{mmol} / \mathrm{L})$ & $18.8 \pm 4.2$ & 17.0 & 19.3 & 20.5 & 25.4 & $27.4 \pm 4$ & 25.2 & 27.3 & 29.1 & 32.4 & $<0.0001$ \\
\hline $\mathrm{TCO}_{2}(\mathrm{mmol} / \mathrm{L})$ & $19.7 \pm 4.4$ & 18.0 & 19.5 & 21.8 & 25.0 & $27.5 \pm 4.1$ & 25.3 & 28.0 & 29.8 & 33.6 & 0.0001 \\
\hline $\mathrm{SO}_{2}(\%)$ & $55 \pm 8$ & 49 & 53 & 61 & 65 & $65.3 \pm 6.6$ & 64 & 65 & 69 & 73 & 0.0006 \\
\hline AnGap (mmol/L) & $21.0 \pm 3.2$ & 18.3 & 20.5 & 22.8 & 25.3 & $4.1 \pm 0.5$ & 3.9 & 4.1 & 4.3 & 4.7 & 0.0001 \\
\hline
\end{tabular}

$\mathrm{PCO}_{2}=$ Partial pressure of carbon dioxide, $\mathrm{PO}_{2}=$ Partial pressure of oxygen, $\mathrm{BE}=$ Base excess, $\mathrm{HCO}_{3}=\mathrm{Bicarbonate}$, $\mathrm{TCO}_{2}=$ Total carbon dioxide, $\mathrm{SO}_{2}=$ Oxygen saturation, AnGap=Anion gap

Table-2: Hematological parameters in goats with contagious caprine pleuropneumonia versus healthy goats.

\begin{tabular}{|c|c|c|c|c|c|c|c|c|c|c|c|}
\hline \multirow[t]{3}{*}{ Parameters } & \multicolumn{5}{|c|}{ Whole blood $(n=38)$} & \multicolumn{5}{|c|}{ Healthy goats $(n=15)$} & \multirow[t]{3}{*}{ p-value } \\
\hline & \multirow[t]{2}{*}{ Mean \pm SD } & \multicolumn{4}{|c|}{ Percentiles (\%) } & \multirow[t]{2}{*}{ Mean \pm SD } & \multicolumn{4}{|c|}{ Percentiles (\%) } & \\
\hline & & 25 & 50 & 75 & 95 & & 25 & 50 & 75 & 95 & \\
\hline WBCs $\left(\times 10^{9} / \mathrm{L}\right)$ & $20.4 \pm 15.2$ & 9.1 & 15.7 & 30.3 & 50.2 & $14.6 \pm 3.6$ & 12.3 & 15.3 & 16.9 & 18.8 & 0.008 \\
\hline LYM $\left(\times 10^{9} / \mathrm{L}\right)$ & $7.3 \pm 6.9$ & 2.3 & 4.5 & 9.4 & 22.1 & $6.2 \pm 3.2$ & 4.8 & 5.6 & 6.5 & 10.0 & 0.4 \\
\hline MON $\left(\times 10^{9} / \mathrm{L}\right)$ & $0.5 \pm 1.0$ & 0.1 & 0.2 & 0.3 & 2.8 & $0.9 \pm 3.9$ & 0.1 & 0.1 & 0.1 & 0.2 & 0.7 \\
\hline NEU $\left(\times 10^{9} / \mathrm{L}\right)$ & $12.7 \pm 10.9$ & 4.7 & 8.0 & 22.0 & 33.3 & $9.3 \pm 4.1$ & 6.5 & 8.7 & 11.0 & 17.4 & 0.008 \\
\hline $\operatorname{RBCs}\left(\times 10^{12} / \mathrm{L}\right)$ & $14.1 \pm 5.1$ & 10.2 & 13.9 & 17.8 & 21.5 & $16.6 \pm 2.1$ & 14.9 & 16.5 & 17.6 & 20.0 & 0.0005 \\
\hline $\mathrm{HB}(\mathrm{g} / \mathrm{dL})$ & $13.0 \pm 4.1$ & 8.1 & 9.9 & 11.2 & 13.7 & $12.0 \pm 2.7$ & 9.5 & 10.6 & 11.5 & 12.2 & 0.03 \\
\hline НCT (\%) & $24.7 \pm 8.2$ & 20.6 & 25.6 & 27.0 & 35.1 & $26.1 \pm 3.2$ & 23.3 & 26.2 & 28.7 & 29.8 & 0.2 \\
\hline
\end{tabular}

WBCs $=$ White blood cells, LYM=Lymphocyte, MON=Monocyte, NEU=Neutrophil, RBCs=Red blood cells, HB=Hemoglobin, $\mathrm{HCT}=$ Hematocrit 
Available at www.veterinaryworld.org/Vol.14/July-2021/21.pdf

Table-3: Biochemical parameters in goats with contagious caprine pleuropneumonia versus healthy control goats.

\begin{tabular}{|c|c|c|c|c|c|c|c|c|c|c|c|}
\hline \multirow[t]{3}{*}{ Parameters } & \multicolumn{5}{|c|}{ Whole blood $(n=38)$} & \multicolumn{5}{|c|}{ Healthy goats $(n=15)$} & \multirow[t]{3}{*}{ p-value } \\
\hline & \multirow[t]{2}{*}{ Mean \pm SD } & \multicolumn{4}{|c|}{ Percentiles (\%) } & \multirow[t]{2}{*}{ Mean士SD } & \multicolumn{4}{|c|}{ Percentiles (\%) } & \\
\hline & & 25 & 50 & 75 & 95 & & 25 & 50 & 75 & 95 & \\
\hline ALB (G/L) & $33.5 \pm 7.4$ & 26.8 & 32.5 & 40.5 & 43.3 & $44.8 \pm 2.3$ & 43.0 & 44.0 & 47.0 & 48 & $<0.0001$ \\
\hline ALP (U/L) & $34 \pm 25$ & 21 & 28 & 34 & 76 & $85 \pm 27$ & 59 & 83 & 105 & 128 & $<0.0001$ \\
\hline AST (U/L) & $155 \pm 160$ & 83 & 107 & 147 & 306 & $73 \pm 20$ & 54 & 67 & 94 & 101 & 0.03 \\
\hline CA (MMOL/L) & $1.9 \pm 0.5$ & 1.9 & 2.0 & 2.2 & 2.5 & $2.3 \pm 0.2$ & 2.2 & 2.4 & 2.5 & 2.6 & 0.003 \\
\hline GGT $(U / L)$ & $67 \pm 36$ & 47 & 54 & 74 & 113 & $42 \pm 7$ & 37 & 42 & 45 & 52 & 0.003 \\
\hline $\mathrm{TP}(\mathrm{G} / \mathrm{L})$ & $68.7 \pm 9.4$ & 61.8 & 71.0 & 74.0 & 82.5 & $72.3 \pm 6$ & 69 & 73 & 76 & 79 & 0.1 \\
\hline GLOB (G/L) & $35.6 \pm 9.7$ & 29.8 & 34.5 & 39.8 & 51.9 & $27.9 \pm 5.0$ & 25 & 29 & 30 & 35 & 0.004 \\
\hline BUN (MG/dL) & $11.2 \pm 11.8$ & 4.25 & 6.5 & 14.0 & 36.0 & $3.6 \pm 1.7$ & 2.5 & 3.4 & 4.2 & 5.7 & 0.008 \\
\hline CK (U/L) & $378 \pm 649$ & 152 & 173 & 312 & 109 & $177 \pm 59$ & 128 & 155 & 227 & 264 & 0.1 \\
\hline PHOS (MMOL/) & $1.7 \pm 0.6$ & 1.4 & 1.7 & 2.0 & 2.4 & $2.1 \pm 0.8$ & 1.2 & 2.2 & 2.8 & 3.0 & 0.1 \\
\hline MG (MMOL/L) & $0.7 \pm 0.3$ & 0.6 & 0.7 & 0.9 & 1.1 & $1.2 \pm 0.5$ & 0.8 & 1.0 & 1.5 & 1.8 & 0.001 \\
\hline GLU (MG/dL) & $116 \pm 30$ & 95 & 109 & 142 & 154 & $78 \pm 26$ & 62.5 & 68.5 & 89.5 & 113.5 & 0.005 \\
\hline
\end{tabular}

$\mathrm{TP}=$ Total protein, $\mathrm{ALB}=$ Albumin, $\mathrm{ALP}=\mathrm{Alk}$ aline phosphatase, $\mathrm{AST}=\mathrm{Aspartate}$ aminotransferase, $\mathrm{CA}=\mathrm{Calcium}$, $\mathrm{GGT}=\mathrm{\gamma}$-glutamyl transferase, $\mathrm{GLOB}=$ Globulin, BUN=Blood urea nitrogen, $\mathrm{CK}=$ Creatine kinase, $\mathrm{PHOS}=\mathrm{Phosphorus,}$ $M G=$ Magnesium, GLU=Glucose

comparisons with the diseased group. Normally, a small quantity of fluid is found in the thoracic, pericardial, and abdominal cavities, providing lubrication and preventing friction between adjacent organs and the body cavity walls [15]. Effusions of these cavities refer to the excessive accumulation of fluids in these cavities, which are prevalent in veterinary medicine [16]. The etiology of cavity fluid accumulation includes cardiovascular disorders, neoplasia, trauma, and hypoalbuminemia. Suitable collection and appropriate evaluation of body cavity fluids can supply the practitioners with valuable information that assists in recognizing the disease process that causes fluid accumulation [10]. In goats with advanced CCPP, profuse straw-colored fluid accumulates in the pleural cavity [17-19].

In the host organism, homeostasis is stimulated as a result of any bacterial infection in different ways based on the pathogen itself, site of infection, pathology, and severity of infection [20]. In the current study, the acid-base parameters were investigated in goats with CCPP due to Mccp infection and, although the difference was not significant, the blood $\mathrm{pH}$ in goats with CCPP was higher than that in controls. This increase could be easily explained by the increase in respiratory rate and loss of $\mathrm{CO}_{2}$ during expiration. The significant decreases of blood $\mathrm{PCO}_{2}, \mathrm{TCO}_{2}, \mathrm{HCO}_{3}$, and $\mathrm{BE}$ also support this explanation. The $\mathrm{BE}$ constitutes $\mathrm{HCO}_{3}$ and other basic elements, and therefore, $\mathrm{BE}$ is considered a more sensitive indicator of metabolic acidosis than only $\mathrm{HCO}_{3}$ [21]. In this study, the low values of $\mathrm{HCO}_{3}, \mathrm{BE}$, and $\mathrm{TCO}_{2}$ may be justified due to the metabolic acidosis, which is the cause of why BE mean values were negative. Another indicator of the resulting metabolic acidosis in goats with CCPP in this study was the significant difference in the level of AnGap [22].

Concerning the hematobiochemical parameters in goats with CCPP, neutrophilic leukocytosis, and decreased RBC count were the outstanding significant findings. Interestingly, the numbers of WBCs and neutrophils were also high in thoracic fluid. The results of leukocytosis and anemia agree well with those obtained by Abdelsalam et al. [23] and Mondal et al. [24]. Usually, in field cases, hematological findings are not so relevant to the diagnosis of CCPP [1]. Similar findings of increased globulin, glucose, and AST and decreased albumin have also been reported by Mondal et al. [24]. In this study, the reason why the activities of ALP, AST, GGT, and CK were higher in thoracic fluid than in serum may be the severe pulmonary damage.

\section{Conclusion}

It is concluded from this study that goats with CCPP have metabolic acidosis when compared with healthy controls. Compared with the values in healthy goats, the blood levels of $\mathrm{PCO}_{2}, \mathrm{PO}_{2}, \mathrm{BE}, \mathrm{HCO}_{3}$, $\mathrm{TCO}_{2}$, and $\mathrm{SO}_{2}$ were low in goats with CCPP; however, the AnGap was higher in the diseased goats. A limitation of this study was the failure to collect thoracic samples from the healthy group for comparisons with diseased goats. A future study is, therefore, warranted to collect thoracic samples from healthy goats at a slaughterhouse for comparisons with thoracic samples of goats affected by CCPP.

\section{Author's Contributions}

MT: Designed and performed the experiment, analyzed the data, wrote and revised the manuscript, and prepared the tables. The author has read and approved the final manuscript.

\section{Acknowledgments}

The author is thankful to Department of Veterinary Medicine, College of Agriculture and Veterinary Medicine, Qassim University, Saudi Arabia for providing the necessary facilities for the study. The author did not receive any funds for this study. 


\section{Competing Interests} interests.

The author declares that he has no competing

\section{Publisher's Note}

Veterinary World remains neutral with regard to jurisdictional claims in published institutional affiliation.

\section{References}

1. Yatoo, M.I., Parray, O.R., Bashir, S.T., Bhat, R.A., Gopalakrishnan, A., Karthik, K., Dhama, K. and Singh, S.V. (2019) Contagious caprine pleuropneumonia-a comprehensive review. Vet. Q., 39(1): 1-25.

2. Ahaduzzaman, M.D. (2021) Contagious caprine pleuropneumonia (CCPP): A systematic review and meta-analysis of the prevalence in sheep and goats. Transbound. Emerg. Dis., 68(3): 1332-1344.

3. Asmare, K., Abayneh, T., Mekuria, S., Ayelet, G., Sibhat, B., Skjerve, E., Szonyi, B. and Wieland, B. (2016) A meta-analysis of contagious caprine pleuropneumonia (CCPP) in Ethiopia. Acta Trop., 158: 231-239.

4. Tharwat, M. and Al-Sobayil, F. (2017) Diagnostic ultrasonography in goats with contagious caprine pleuropneumonia caused by Mycoplasma capricolum subsp. Capripneumoniae. BMC Vet. Res., 13(1): 263.

5. Teshome, D., Sori, T., Sacchini, F. and Wieland, B. (2019) Epidemiological investigations of contagious caprine pleuropneumonia in selected districts of Borana zone, Southern Oromia, Ethiopia. Trop. Anim. Health Prod., 51(3): 703-711.

6. Samiullah, S. (2013) Contagious caprine pleuropneumonia and its current picture in Pakistan: A review. Vet. Med., 58(8): 389-398.

7. March, J.B., Harrison, J.C. and Borich, S.M. (2002) Humoral immune responses following experimental infection of goats with Mycoplasma capricolum subsp. capripneumoniae. Vet. Microbiol., 84(1-2): 29-45.

8. Jean de Dieu, B., Charles, B.S., Nwankpa, N., Chitsungo, E., Boukary, C.R.M., Maina, N., Tefera, T.A., Nwankpa, R.V., Mwangi, N. and Koffi, Y.M. (2019) Development and evaluation of epitope-blocking ELISA for detection of antibodies against contagious caprine pleuropneumonia in goat sera. Vet. Sci., 6(4): 82.

9. Abd-Elrahman, A.H., Khafaga, A.F. and Abas, O.M. (2020) The first identification of contagious caprine pleuropneumonia (CCPP) in sheep and goats in Egypt: Molecular and pathological characterization. Trop. Anim. Health Prod., 52(3): 1179-1186

10. Alleman, A.R. (2003) Abdominal, thoracic, and pericardial effusions. Vet. Clin. N. Am. Food Anim. Pract., 33(1):
$89-118$.

11. Tharwat, M., Ali, A., Al-Sobayil, F. and Buczinski, S. (2013) Ultrasound-guided collection of peritoneal fluid in healthy camels (Camelus dromedarius) and its biochemical analysis. Small Rumin. Res., 113(1): 307-311.

12. Quade, B.N., Parker, M.D. and Occhipinti, R. (2021) The therapeutic importance of acid-base balance. Biochem. Pharmacol., 183: 114278.

13. Tharwat, M. and Al-Sobayil, F. (2014) Cord and jugular blood acid-base and electrolyte status and haematobiochemical profiles in goats with naturally occurring pregnancy toxaemia. Small Rumin. Res., 117(1): 73-77.

14. SPSS. (2017) Statistical Package for Social Sciences. SPSS Inc., Chicago, IL, USA.

15. O'Brien, P.J. and Lumsden, J.H. (1988) The cytologic examination of body cavity fluids. Semin. Vet. Med. Surg. Small Anim., 3(2): 140-156.

16. Dempsey, S.M. and Ewing, P.J. (2011) A review of the pathophysiology, classification, and analysis of canine and feline cavity effusions. J. Am. Anim. Hosp. Assoc., 47(1): $1-11$.

17. DaMassa, A.J., Wakenell, P.S. and Brooks, D.L. (1992) Mycoplasmas of goats and sheep. J. Vet. Diagn. Invest., 4(1): 101-113.

18. Yatoo, M.I., Parray, O.R., Mir, M.S., Qureshi, S., Kashoo, Z.A., Nadeem, M., Fazili, M.U.R., Tufani, N.A., Kanwar, M.S., Chakraborty, S., Dhama, K. and Rana R. (2018) Mycoplasmoses in small ruminants in India: A review. J. Exp. Biol. Agric. Sci., 6(2): 264-281.

19. Hussain, R., Auon, M., Khan, A., Khan, M.Z., Mahmood, F. and UrRehman, S. (2012) Caprine pleuropneumonia in Beetal goats. Trop. Anim. Health Prod., 44(3): 477-481.

20. Bassis, S., Fischer, S., Köhler, H. and Reinhold, P. (2020) Acid-base variables in acute and chronic form of nontuberculous mycobacterial infection in growing goats experimentally inoculated with Mycobacterium avium subsp. hominissuis or Mycobacterium avium subsp. paratuberculosis. PLoS One, 15(12): e0243892.

21. Sigaard-Andersen, O. and Fogh-Andersen, N. (1995) Base excess or buffer base (strong ion difference) as measure of non-respiratory acid-base disturbance. Acta Anaesthesiol. Scand., 107: 123-128.

22. Emmett, M. and Narins, R.G. (1977) Clinical use of the anion gap. Medicine, 56(1): 38-54.

23. Abdelsalam, E.B., Goraish, I.A. and Tartour, G. (1988) Clinico-pathological aspects of naturally-occurring contagious caprine pleuropneumonia in Sudan. Rev. Élev. Méd. Vét. Pays Trop., 41(1): 52-54.

24. Mondal, D., Pramanik, A.K. and Basak, D.K. (2004) Clinico-haematology and pathology of caprine Mycoplasma pneumonia in rain-fed tropics of West Bengal. Small Rumin. Res., 51(3): 285-295. 